\title{
Quelle vision il y a 50 ans des enjeux éthiques en médecine?
}

\section{Jean Martin}

Dr med., membre de la rédaction

Occupation de retraité... je parcourais les rayons de ma bibliothèque et suis tombé sur un livre marquant paru alors que j'étudiais la santé publique aux Etats-Unis [1], issu d'une série de trente conférences à l'Université Stanford. Je me suis replongé dans son chapitre sur les défis éthiques à venir, par un jeune psychiatre américain - qui depuis lors a eu une carrière distinguée [2]. C'était il y a un demi-siècle et j'ai été frappé de voir comment, d'une part, se posaient des questions qui sont les nôtres aujourd'hui encore et, d'autre part, comment nous avons insuffisamment progressé dans leur résolution.

Premières lignes du texte: "L' 'épidémie' récente de transplantations cardiaques et la synthèse d'un ADN viral actif ont suscité un intérêt jamais vu auparavant dans la population générale. Ces débats ont aussi montré comment la médecine est grossièrement mal préparée à traiter les problèmes qui surgissent. Chirurgiens et généticiens ont montré leur trouble, leur désorientation, quant aux enjeux de leurs avancées. Différents groupes et comités ont alors été réunis, mais le public a posé des questions embarrassantes et s'est montré critique de ce qu'on n'ait pas cherché des réponses avant ou pour le moins pendant les travaux scientifiques plutôt que post facto.» Et: «Ces développements illustrent la scène contemporaine s'agissant de technologie: des machines 'indifférentes' (dénuées d'esprit - mindless) vont de l'avant sans relâche, mais elles sont sans moyen de savoir où elles vont ni quels problèmes elles peuvent susciter.»

\section{Le public s'est montré critique de ce qu'on n'ait pas cherché des réponses avant les travaux scientifiques plutôt que post facto.}

Intéressante appréciation. Les choses, malgré la création de centaines de commissions d'éthique à différents niveaux (dans les laboratoires et institutions scientifiques, les hôpitaux, au niveau national sous des auspices publiques et privées, etc.), ont-elles fondamentalement changé?

Fuller Torrey discute quelques développements d'alors, ainsi la contraception - peu après l'arrivée en force de la pilule. Il parle entre autres de congélation de sperme, ouvrant la porte à la paternité posthume, et de création de banques de sperme collectant la semence de gens célèbres... Il évoque l'éventualité de retirer un œuf fécondé de l'utérus de sa mère pour le faire porter par une 'foster mother': "Si des choses de ce type se font, les femmes qui ne veulent pas porter leur propre enfant pourront louer les services d'une mercenaire, variété de fin du $\mathrm{XX}^{\mathrm{e}}$ siècle de la nourrice - employée par les classes aisées de siècles antérieurs.» Prémonitoire, non? - aujourd'hui, la gestation pour autrui est admise et se développe dans plusieurs pays, aussi bien du Nord industrialisé qu'ailleurs. Plus loin: «Bien que la modification directe des chromosomes par une chirurgie génétique soit encore une perspective lointaine, beaucoup de travail est réalisé chez les animaux sur des embryons encore dans l'utérus.» Perspective

\section{Il se préoccupe de la place et du rôle} des médecins dans la société.

plus du tout si lointaine maintenant que nous arrive, à grand renfort de médiatisation, la technique CRISPR d'édition du génome, une sorte de «chirurgie» dont on loue la facilité et l'économicité [3].

Torrey à propos de thérapeutique et de ce qu'on appelle aujourd'hui amélioration/enhancement de l'humain: «Des machines arrivent dans le domaine de la psychiatrie et de l'esprit humain; un psychiatre de Stanford tente de programmer un ordinateur pour traiter ses patients (...) Les usages possibles de machines pour contrôler notre esprit sont illustrés par le travail de Delgado à Yale. Il a implanté des électrodes dans le cerveau de singes, qui rejettent leur progéniture quand ces électrodes sont stimulées.»

A propos de la révolution technologique: «Avant de chercher des réponses, il est nécessaire de comprendre deux caractéristiques de cette révolution: elle est indifférente (mindless) et elle est neutre. Elle est indifférente parce que la science pure est un désir de savoir, de découvrir des secrets; elle est neutre parce que les changements qu'apportent la technologie ne sont en euxmêmes ni bons ni mauvais. Ils acquièrent une valeur seulement par la manière dont on s'en sert. Le potentiel (pour le bien ou le mal) de certains développe- 


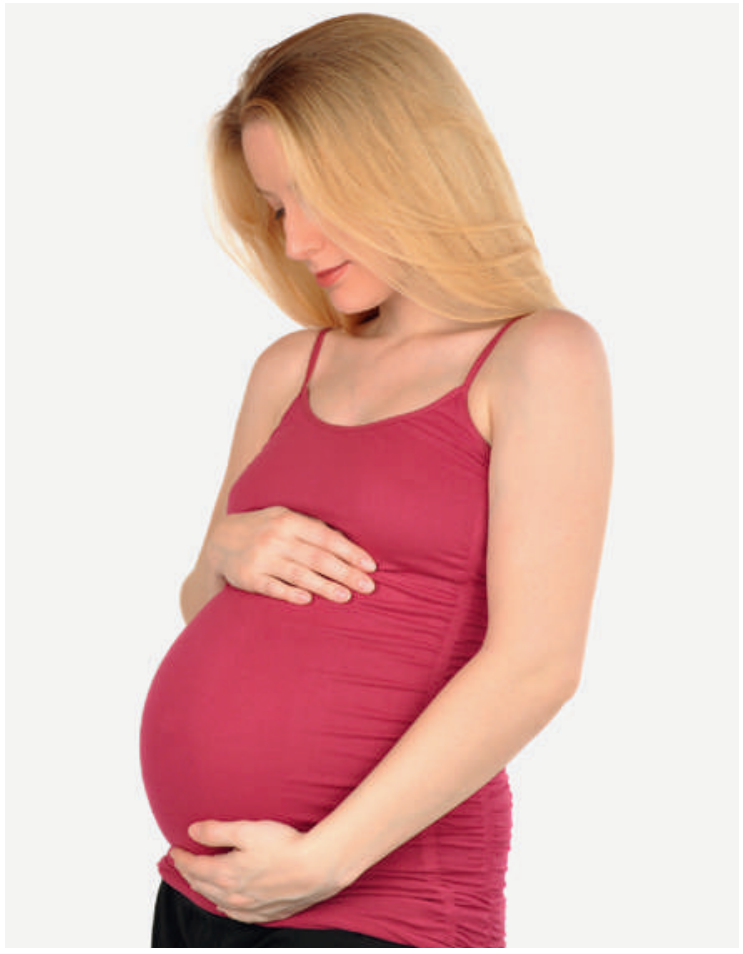

Parmi d'autres enjeux éthiques: des manières inédites, inouïes, de procréer.

ments actuels sont stupéfiants.» Alors... «Parce que cette révolution est indifférente et neutre, et parce que les scientifiques continueront leurs travaux dans quelque direction que ce soit à moins qu'on les enjoigne spécifiquement de ne pas le faire, un contrôle doit être exercé. Il s'agit d'abord de déterminer les valeurs qui comptent. Comme l'a dit le New York Times au lendemain d'Hiroshima, l'humanité peut-elle grandir suffisamment vite pour gagner la course entre la civilisation et le désastre? Ce qu'il faut aujourd'hui c'est monter à bord de cette machine et véritablement diriger sa course. C'est seulement ainsi que science et technologie seront un instrument au service de l'homme plutôt qu'un moyen d'en faire leur esclave.» Cela est souvent dit et répété mais des conséquences pratiques sont-elles assez souvent tirées? Un obstacle à une vision claire des problèmes est selon Torrey la déshumanisation croissante de la société. Il cite Erich Fromm qui a parlé d'une ère «où les humains construisent des machines qui agissent comme des humains et développe des humains qui agissent comme des machines, où les humains deviennent des appendices des processus de production et consommation". Certains diront que cette formule a un côté théâtral mais serait-elle aujourd'hui obsolète?

Il se préoccupe de la place et du rôle des médecins dans la société: «Les réponses générales doivent être formulées par des politiques (policies) publiques. Les pro- blèmes sociaux et philosophiques de la médecine n’appartiennent pas aux seuls docteurs, ou aux théologiens ou aux juristes, ces problèmes sont ceux de tout un chacun. Mais pour que l'opinion publique puisse vraiment s'exprimer, elle doit être informée. C'est là que le rôle du médecin commence. La profession médicale doit jouer un rôle majeur en montrant les faits, en clarifiant les alternatives et en établissant des limites. Elle a aussi une obligation d'assumer un leadership.» Plus loin: «En général, les médecins craignent de jouer à Dieu. Mais ce qu'il faut craindre autant serait l'échec à jouer la partition de l'Homme. Dans le passé, la médecine a été accusée d'adopter une politique de l'autruche sur les enjeux sociaux. Elle ne peut pas se payer le luxe de simplement être assise sur la ligne de touche et d'observer - parce qu'elle a maintenant du pouvoir, un pouvoir croissant.» L'auteur consacre enfin une section au rôle de l'American Medical Association mais relève que celle-ci a jusqu'alors été décevante. "A des rares exceptions près, l'AMA a choisi de suivre plutôt que de conduire en ce qui concerne ces problèmes (...) Ses préoccupations principales ont été les questions de déontologie, de compétence professionnelle et le contrôle des tarifs.» Ces propos de 1970 ne restent-ils pas très actuels? Pourtant, au cours du dernier demi-siècle, ne les avonsnous pas tous vus, lus ou entendus à réitérées reprises?

\section{Un obstacle à une vision claire des problèmes} est selon Torrey la déshumanisation croissante de la société.

Le fait est que ces questionnements n'ont pas diminué de gravité - tout indique qu'ils se sont alourdis. Malgré la multiplication des comités d'éthique, on traite surtout (avec sérieux et intelligence) de questions partielles, en ne trouvant pas le temps de consacrer assez d'attention à la «big picture», aux questions «surplombantes" de l'évolution de la biomédecine et de la société. On peut d'ailleurs le comprendre (mais ce n'est pas une excuse!), il est plus ardu de chercher ce qui est juste du point de vue des évolutions générales qui mettent en jeu l'avenir de la cité et impliquent des appréciations de valeurs qui peuvent diverger entre les personnes et les groupes - que de formuler des recommandations pour la bonne réalisation d'études scientifiques. On sait établir des règles pour que ces études protègent adéquatement les droits et intérêts des participants à la recherche mais sait-on préserver les droits et intérêts de la cité en général, et de ceux qui nous suivent, des générations futures? Pas sûr.

Crédit photo

(c) Haywiremedia | Dreamstime.com 